\title{
Stability of the regional stress field in central Japan during the late Quaternary inferred from the stress inversion of the active fault data
}

\section{$\operatorname{AUTHOR}(S):$}

Tsutsumi, Hiroyuki; Sato, Katsushi; Yamaji, Atsushi

\section{CITATION:}

Tsutsumi, Hiroyuki ... [et al]. Stability of the regional stress field in central Japan during the late Quaternary inferred from the stress inversion of the active fault data. Geophysical Research Letters 2012, 39(23): L23303.

\section{ISSUE DATE:}

2012-12

URL:

http://hdl.handle.net/2433/167965

\section{RIGHT:}

(C)2012. American Geophysical Union.; This is not the published version. Please cite only the published version.; この論文は出版社版でありませ ん。引用の際には出版社版をご確認ご利用ください。 
1 Stability of the regional stress field in central Japan during the late Quaternary

2 inferred from the stress inversion of the active fault data

3

$4 \quad$ Hiroyuki Tsutsumi ${ }^{1}$, Katsushi Sato ${ }^{1}$, and Atsushi Yamaji ${ }^{1}$

$5 \quad{ }^{1}$ Division of Earth and Planetary Science, Graduate School of Science, Kyoto University,

6 Kyoto 606-8502, Japan 


\section{ABSTRACT}

8 We analyzed 169 geological fault-slip data from 37 active faults in central Japan to

9 investigate the late Quaternary stress field stability. Modern stress states have been

10 documented with unprecedented accuracy; however, their stability over time scales

11 beyond instrumental observations is inadequately understood. Because the stress field

12 has changed in the geological past, we compared present stress conditions in central

13 Japan, determined from geophysical observations, with conditions determined by

14 inverting the fault-slip data from active faults that exhibited cumulative displacement

15 for the past $\sim 10^{5}$ years. The maximum stress axis obtained from fault-slip data trends

16 ESE-WNW. This state of stress accounts for $97 \%$ of the data and supports the fact that

17 oblique faults with reverse and strike-slip senses are interlaced in the region. The

18 optimal stress is similar to the present stress state, indicating that the stress field in

19 central Japan has been uniform and stable over the past $\sim 10^{5}$ years.

\section{Introduction}

The crustal stress field is one of the most important parameters required to understand tectonics, but the secular variation or stability of tectonic stress is not

24 adequately understood for the time scales of $10^{3}-10^{5}$ years. The World Stress Map

25 (WSM) Project was the first coordinated effort to map tectonic stress fields worldwide 26 [Zoback, 1992], and the WSM database released in 2008 [Heidbach et al., 2010]

27 contains three times as much stress data as that of the 1992 database. Most of the data sets used to derive the stress fields in the project are geophysical data such as those derived from the focal-mechanism solutions of earthquakes and wellbore breakout. In 
31 for only $\sim 10 \%$ of the total data [Zoback, 1992; Heidbach et al., 2010]. The geophysical

32 data reveal stress fields on the time scales of $10^{0}-10^{2}$ years, whereas the geological data

33 reveal stress fields over longer periods, usually $10^{5}$ years or longer. Active faults are the

34 clues that will help in filling the gap between the time scales of geophysical and

35 geological observations because their intermittent but steadily growing displacements

36 over the last $10^{3}-10^{5}$ years are evident from, e.g., geomorphology, paleoseismic

37 trenching, and seismic-reflection profiling. Central Japan is suitable for crustal

38 stress-field analyses on different time scales because it contains one of the world's

39 highest-quality geophysical [e.g., Mazzotti et al., 2001; Townend and Zoback, 2006;

40 Terakawa and Matsu'ura, 2010] and geological [e.g., The Research Group for Active

41 Faults of Japan, 1991; Nakata and Imaizumi, 2002] data sets.

42 Permanent regional strain in central Japan has been accommodated mainly by active

43 faults, which form a dense network in the region [The Research Group for Active Faults

44 of Japan, 1991; Nakata and Imaizumi, 2002] (Figure 1). Since the 1995 Kobe

45 earthquake, most of the long and fast-slipping faults in the region have been studied

46 extensively through a national active-fault research program, which has produced one of

47 the most comprehensive active-fault data sets in the world. Therefore, non-Andersonian

48 faults have gradually become clear; reverse and strike-slip faults are interlaced in this

49 region. In addition, a few of these types of faults have trends subparallel to each other

50 while exhibiting different dip angles: the Hanaore and Biwako-seigan faults represent

51 such a pair and are interpreted as an example of strain partitioning (Figure 1). Active

52 faulting and its relation to the stress field in central Japan have been a topic of debate

53 [Huzita, 1968; Okada and Ando, 1979], but the coexistence of faults with different

54 senses of motion makes inference difficult without the inclusion of a special type of 
stress-tensor inversion, as described below.

Stress-tensor inversion is used to determine stress conditions from the fault-slip data.

Each datum comprises the attitude of a fault and the slip direction on the fault plane [e.g., Angelier, 1979] (Figure 2a). However, the slip directions are seldom determined along the segments of active faults. Instead, the directions are vaguely documented in the terms of slip senses. For example, the slip direction of a reverse fault has an uncertainty of $180^{\circ}$ with respect to the rake direction; the dip occurs at the center of possible slip directions for the footwall block (Figure 2b). Similarly, the slip direction of a strike-slip fault has an uncertainty of $180^{\circ}$, but the possible slip direction is horizontal from the center of the slip. A few active faults in central Japan are described as oblique reverse faults with sinistral or dextral components. The slip directions of these faults have an uncertainty of $90^{\circ}$ (Figure 2c). A fault-slip data set for active faults in central Japan includes such deficiencies. Lisle et al. [2001] developed a pioneering stress-inversion method to deal with sense-only data. Recently, Sato [2006] developed a special type of stress-inversion method to deal with mixed set of complete and sense-only fault-slip data.

In this study, we apply Sato's [2006] method to the active fault data to derive the regional stress field in central Japan. Although the slip inversion of a single active fault was conducted by Blenkinsop [2006] for the Chelungpu fault that ruptured during the 1999 Chi-Chi earthquake in Taiwan, this is the first study to reveal a regional stress field based on the stress inversion analysis of a large set of the active fault data. We show that central Japan is under an ESE-WNW compressional stress field with a small stress ratio, $\Phi=\left(\sigma_{2}-\sigma_{3}\right) /\left(\sigma_{1}-\sigma_{3}\right)$, and that the regional stress field has been uniform and stable over the past $\sim 10^{5}$ years. 


\section{Tectonic setting}

To the east of the Japanese islands, the Pacific plate is subducted westward beneath the North American and Philippine Sea plates (Figure 1). Along the Nankai trough, the

83 Philippine Sea plate has been subducting northwestward since the Pliocene or mid-Pleistocene [e.g., Seno and Maruyama, 1984; Yamaji, 2000]. In the study area, i.e., the eastern part of the southwest Japan arc, north-trending reverse faults and northwest-trending left-lateral and northeast-trending right-lateral strike-slip faults are densely distributed (Figure 1). The offsets of dated geomorphic features indicate slip rates in the order of $10^{-1}$ to $10^{0} \mathrm{~mm} / \mathrm{yr}$ for such faults [The Research Group for Active Faults of Japan, 1991]. Central Japan has a long historical earthquake record that has been systematically collected for several centuries [Usami, 2003; Ishibashi, 2004]. The area has experienced one reverse-slip and four strike-slip earthquakes that ruptured the surface since the 1891 Nobi earthquake (Figure 1).

93 Geodetic and seismological data show that the Japan arc is subject to an

94 approximate E-W compression. Mazzotti et al. [2001] calculated the permanent deformation field in central Japan by subtracting short-term elastic deformation related to the locking of the plate interface along the Nankai trough from GPS observations, and they obtained the residual-deformation field indicating ESE-WNW shortening. Townend and Zoback [2006] reported that the maximum horizontal stress is oriented approximately toward ENE-WSW in southwest Japan. Terakawa and Matsu'ura [2010] used the centroid-moment-tensor data to show that the tectonic stress of the Japan arc is

101 basically an E-W compression with the direction of intermediate principal stress 102 changing from $\mathrm{N}-\mathrm{S}$ in northeast Japan to vertical in southwest Japan. 


\section{Data}

After the 1995 Kobe earthquake, the Headquarters for Earthquake Research

106 Promotion (HERP) of the Japanese government selected approximately 100 inland

107 active faults and conducted extensive geological and paleoseismological studies to assess their seismic potential. We compiled the fault-slip data from 36 active faults selected by HERP in the Chubu and Kinki districts, to the west of the Itoigawa-Shizuoka tectonic line and east of the Nojima fault that ruptured during the

1111995 Kobe earthquake (Figure 1). To exclude local-stress perturbation due to the 112 collision of the Izu Peninsula with the main island of Japan [e.g., Mazzotti et al., 2001;

113 Townend and Zoback, 2006] from our regional stress analysis, we analyzed the data for

114 the faults to the west of the Itoigawa-Shizuoka tectonic line, which is part of the

115 postulated plate boundary between the North American and Eurasian plates [Nakamura, 116 1983]. We examined data from paleoseismic trench walls, natural outcrops, and seismic 117 reflection profiles in published reports and maps. To determine the stress regime for a 118 time scale of $10^{5}$ years, we compiled the data on faults that clearly offset geomorphic 119 surfaces or strata of late Quaternary age dated by tephrochronology or radiometric 120 methods. Therefore, we catalogued reliable fault orientations and slip senses at 166 sites 121 along 36 faults (Table S1 in the auxiliary material). In addition, we catalogued the data 122 from three sites along the Fukozu fault, the source fault of the 1945 Mikawa earthquake

123 that was not selected by HERP but for which extensive paleoseismic trenching was 124 conducted [e.g., Sone and Ueta, 1993].

125 The fault-slip data set used in this study had a few deficiencies. Slickenlines were 126 observed to determine the rakes of slip vectors at only 11 sites out of 169 . We obtained 
127 the "complete" data for 11 sites, and the remaining sites produced "sense-only" data,

128 which have the rake uncertainties of $90^{\circ}$ or $180^{\circ}$ (Figures $2 \mathrm{~b}$ and c). Figures $2 \mathrm{~d}-\mathrm{f}$

129 illustrate the tangent-lineation diagrams [Twiss and Gefell, 1990], improved by Sato

130 [2006], that display the fault attitude and possible slip directions of the complete and

131 sense-only data. A complete datum is denoted by an arrow plotted by a

132 lower-hemisphere, equal-area projection; the pole of the fault plane is depicted in the

133 stereogram by the position of the arrow, which itself indicates the slip direction of the

134 footwall block (Figure 2d). The inward and outward directions of the arrow indicate the

135 reverse and normal senses of shear, respectively. Strike-slip faults are represented by

136 such arrows that are directed perpendicular to the radial directions in the plot. A

137 sense-only datum is denoted by a semicircle or fan, which indicates the possible slip

138 direction of the footwall block (Figures 2e and f). Figure 3 shows the fault-slip data

139 from the active faults in the study area; we recorded a large variation of fault attitudes

140 from 169 sites distributed along 37 faults.

\section{4. Stress inversion}

143 The stress-inversion method proposed by Sato [2006] was employed to determine

144 the stress conditions that explain the mixed set of the complete and sense-only data. The

145 method can deal with both the complete and sense-only data by placing tighter and

146 looser constraints on the conditions, respectively. The Wallace-Bott hypothesis is

147 assumed, as is customary: the slip directions of faults are assumed to be parallel to the

148 resolved shear stresses (theoretical slip directions) on the fault planes, which are

149 calculated from the fault attitudes and stress conditions. The fitness of arbitrary stress

150 conditions to a datum, i.e., how preferable is the assumption for a fault, is defined as a 
151 decreasing function of the misfit angle $d$ between the theoretical and observed slip

152 directions (Figure $2 \mathrm{~g}$ ). The threshold in the function $d_{T}$ is set to $30^{\circ}$ in this study. For the

153 sense-only data, the misfit angles are measured from the center of possible slip

154 directions, and the degrees of fit are equal within the possible range (Figures $2 \mathrm{~h}$ and $\mathrm{i}$ ).

155 According to Sato [2006], all the types of fitness functions are normalized as

156 probability-density functions in the parameter space of deviatoric stress, which is

157 represented schematically as the heights of fitness values in Figures $2 \mathrm{~g}-\mathrm{i}$. The degrees

158 of fit are added over the entire set of the complete and sense-only data to provide a total

159 fitness of stress conditions. The optimal stress conditions are searched to maximize the

160 total fitness. Although the complete data are uncommon in our database (Figure 3 and

161 Table S1), the large variation of fault orientations and large number of data enable us to

162 obtain a stress state with a relatively high precision.

163 Figure 4 shows the optimal stress for our data. A reverse-faulting stress-regime with

164 an ESE-WNW-trending $\sigma_{1}$-axis was found to be capable of explaining almost all the

165 data. The stress ratio, $\Phi=\left(\sigma_{2}-\sigma_{3}\right) /\left(\sigma_{1}-\sigma_{3}\right)$, was determined to be 0.09 , which means

166 that the magnitude of $\sigma_{2}$ is approximately equal to that of $\sigma_{3}$. In addition, Figure 4

167 illustrates the uncertainty of the solution by plotting principal stress axes that have

168 fitness values greater than $90 \%$ of those of the optimal solution. Because of the small $\Phi$

169 value (axial compressional stress), the $\sigma_{3}$-axis has a greater uncertainty than that of the

$170 \sigma_{1}$-axis. We calculated theoretical slip directions for the faults by assuming optimal

171 stress; white arrows in Figure 5 denote these directions.

172

173 5. Discussion 
174 Despite the large variation of fault orientations (Figures 1 and 3), stress inversion

175 revealed that almost all the active faults in the study area are consistent with a

176 reverse-faulting stress regime with ESE-WNW-trending $\sigma_{1}$-axis (Figure 5). The

177 theoretical slip directions of the faults calculated with this optimal stress were consistent

178 with all the data except for five of them. Some of these exceptions have fault planes

179 nearly perpendicular to the optimal $\sigma_{1}$-axis. Theoretical slip directions on such fault

180 planes are unstable as is shown by the radial pattern around the $\sigma_{1}$-axis in Figure 5.

181 Therefore, small perturbations in fault attitudes can explain the large misfits.

182 The optimal stress ratio of 0.09 indicates that $\sigma_{2}$ and $\sigma_{3}$ have similar values. Such a

183 state of stress allows the coexistence of reverse and strike-slip faults, provided that they

184 have different fault orientations. Their coexistence puzzled previous researchers who

185 inferred the stress field from active faults in Japan because they assumed Andersonian

186 faulting [Huzita, 1968; Okada and Ando, 1979]. Consequently, they neglected the

187 coexistence of reverse and strike-slip faults or they had to infer spatially or temporarily

188 complicated stress fields.

189 Although the ESE-WNW compression determined from active faults in this study is

190 generally the same as that proposed by Huzita [1968], we demonstrated that a single

191 state of stress explains the fault-slip data from all sites except five of them. This means

192 that the stress field in central Japan has been uniform and that the active faults have

193 slipped in the same directions over the past $\sim 10^{5}$ years. From the coexistence of reverse

194 and strike-slip faults, we predicted that non-Andersonian, oblique-slip faulting is

195 common in this region although the rakes of slip vectors were observed for only 10 of

19637 faults.

197 The reactivation of the pre-existing planes of weakness gives rise to the 
non-Andersonian faulting of planes with a wide variety of orientations. Kano [2002]

suggested that a few active faults are present in such planes in the Mesozoic accretionary complex in the northern part of the study area. For example, the left-lateral Yanagase fault (Figure 1) reactivated a kink plane of a map-scale chevron fold.

Similarly, the right-lateral Hanaore fault (Figure 1) lies along the axial surface of a fold structure [Kano, 2002]. Ito [2006] obtained the apatite fission track ages of $~ 20$ Ma for dikes intruded along the Yanagase fault, which provides a minimum age constraint for the fault. Murakami and Tagami [2004] conducted the zircon fission-track analysis of pseudotachylyte sampled from the Nojima fault (Figure 1). They suggested that the Nojima fault was already initiated at $\sim 56 \mathrm{Ma}$. The active Median Tectonic Line (Figure 1) follows part of the boundary between the Ryoke and Sanbagawa terranes that were accreted in the Mesozoic [Hashimoto, 1991]. Therefore, a few active faults in central Japan reactivated the pre-existing faults under the present-day stress regime.

Slip on the active faults catalogued in this study reflects the average stress regime in the late Quaternary. The inverted stress state determined in this study is principally consistent with that obtained by geodetic and seismological data [Mazzotti et al., 2001; Townend and Zoback, 2006; Terakawa and Matsu'ura, 2010], suggesting that the stress state in central Japan has been uniform and stable for the past $\sim 10^{5}$ years.

\section{Conclusions}

A dense distribution and an extensive data set of active faults in central Japan has provided us with an exceptional opportunity to invert the regional stress field over a

220 time scale of $\sim 10^{5}$ years. We obtained an optimal state of stress, which is essentially the 
222 in the eastern part of southwest Japan has been stable over the past $\sim 10^{5}$ years.

223 Moreover, the inversion results provide a clear explanation for the coexistence of

224 reverse and strike-slip faults in central Japan. Geological observations suggest that a

225 few active faults in central Japan reactivated pre-existing faults under the present-day

226 stress regime.

227

Acknowledgments

229

We thank Ritsuko Matsu'ura at the Association for the Development of Earthquake

230 Prediction for access to the literature on the active faults used in this study and Shigeru

231 Sueoka for his assistance in compiling the active fault database. We are grateful to

232 Richard Lisle and Robert Yeats for constructive reviews.

\section{References}

235 Angelier, J. (1979), Determination of the mean principal directions of stresses for a 236 given fault population, Tectonophysics, 56, T17-T26.

237 Blenkinsop, T. G. (2006), Kinematic and dynamic fault slip analyses: implications from 238 the surface rupture of the 1999 Chi-Chi, Taiwan, earthquake, J. Struct. Geol., 28, $239 \quad 1040-1050$.

240 Hashimoto, M. (Ed.) (1991), Geology of Japan, Terra Scientific Publishing Company, 241 Tokyo.

242 Heidbach, O, M. Tingay, A. Barth, J. Reinecker, D. Kurfeß, and B. Müller (2010), 243 Global crustal stress pattern based on the World Stress Map database release 2008, 244 Tectonophysics, 428, 3-15.

245 Huzita, K. (1968), Rokko movements and its appearance: intersecting structural patterns 
246 of southwest Japan and Quaternary crustal movements, Quaternary Res., 7, 248-260.

247 (in Japanese with English abstract)

248 Ishibashi, K. (2004), Status of historical seismology in Japan, Ann. Geophys., 47, $249 \quad 339-368$.

250 Ito, H. (2006), Early Miocene igneous activity around northern part of the Yanagase 251 fault and constraints on its fault activity from fission-track thermochronology, J. Geol. 252 Soc. Japan, 112, 612-615. (in Japanese with English abstract)

253 Kano, K. (2002), Steeply-plunging, map-scale folds in the Mino-Tanba Belt, Southwest 254 Japan: origin of the Yanagase Fault as viewed from the basement structures, J. Geol. 255 Soc. Japan, 108, 591-605. (in Japanese with English abstract)

256 Kikuchi, M., and H. Kanamori (1996), Rupture process of the Kobe, Japan, earthquake 257 of Jan. 17, 1995, determined from teleseismic body waves, J. Phys. Earth, 44, $258 \quad 429-436$.

259 Lisle, R., T. Orife, and L. Arlegui (2001), A stress inversion method requiring only slip $260 \quad$ sense, J. Geophys. Res., 106, 2281-2289.

261 Mazzotti, S., P. Henry, and X. Le Pichon (2001), Transient and permanent deformation 262 of central Japan estimated by GPS: 2. Strain partition and arc-arc collision, Earth 263 Planet. Sci. Lett., 184, 455-469.

264 Murakami, M., and T. Tagami (2004), Dating pseudotachylyte of the Nojima fault using 265 the zircon fission-track method, J. Geophys. Res., 31, L12604, 266 doi:10.1029/2004GL020211.

267 Nakamura, K. (1983), Possible nascent trench along the eastern Japan Sea as the 268 convergent boundary between Eurasian and North American plates, Bull. Earthq. Res. 269 Inst. Univ. Tokyo, 58, 711-722. (in Japanese with English abstract) 
270 Nakata, T., and T. Imaizumi (Eds.) (2002), Digital Active Fault Map of Japan,

271 University of Tokyo Press, Tokyo. (in Japanese)

272 Okada, A., and M. Ando (1979), Active faults and earthquakes in Japan, Kagaku, 49, 273 158-169. (in Japanese)

274 Sato, K. (2006), Incorporation of incomplete fault-slip data into stress tensor inversion, 275 Tectonophysics, 421, 319-330.

276 Seno, T., and S. Maruyama (1984), Paleogeographic reconstruction and origin of the 277 Philippine Sea, Tectonophysics, 102, 53-84.

278 Shiono, K. (1977), Focal mechanisms of major earthquakes in southwest Japan and 279 their tectonic significance, J. Phys. Earth, 25, 1-26.

280 Sone, K., and K. Ueta (1993), Trenching study of the Fukozu fault at Tokoji, Aichi 281 Prefecture in 1988, Active Fault Res., 11, 43-46. (in Japanese)

282 Terakawa, T., and M. Matsu'ura (2010), The 3-D tectonic stress fields in and around 283 Japan inverted from centroid moment tensor data of seismic events, Tectonics, 29, 284 TC6008, doi: 10.1029/2009TC002626.

285 The Research Group for Active Faults of Japan (Ed.) (1991), Active Faults in Japan: 286 Sheet Maps and Inventories (revised edition), University of Tokyo Press, Tokyo. (in 287 Japanese with English abstract)

288 Townend, J., and M. D. Zoback (2006), Stress, strain, and mountain building in central 289 Japan, J. Geophys. Res., 111, B03411, doi: 10.1029/2005JB003759.

290 Twiss, R. J., and M. J. Gefell (1990), Curved slickenfibers - a new brittle shear sense 291 indicator with application to a sheared serpentinite, J. Struct. Geol., 12, 471-481. 292 Usami, T. (2003), Materials for Comprehensive List of Destructive Earthquakes in 293 Japan (latest edition), University of Tokyo Press, Tokyo. (in Japanese) 
294 Yamaji, A. (2000), The multiple inverse method applied to meso-scale faults in

295 mid-Quaternary fore-arc sediments near the triple junction off central Japan, J. Struct.

296 Geol., 22, 429-440.

297 Zoback, M. L. (1992), First- and second-order patterns of stress in the lithosphere: the 298 World Stress Map project, J. Geophys. Res., 97, 10703-11728.

299

$300 \quad$ Figure captions

301 Figure 1. Tectonic setting and distribution of active faults in the Kinki and Chubu 302 districts of central Japan. The active fault traces (red lines) are from Nakata and $303 \quad$ Imaizumi [2002], and black arrows denote major strike-slip faults. Blue crosses 304 denote the locations of outcrops, trench sites, and seismic-reflection profiles from 305 where the fault-slip data were collected. Focal-mechanism solutions for historical surface-rupturing earthquakes are also shown by Shiono [1977] and Kikuchi and Kanamori [1996]: 1891 Nobi, 1927 Kita-Tango, 1945 Mikawa, 1948 Fukui, and 1995 Kobe earthquakes. Active faults mentioned in the text are Biwako-seigan fault: BF, Fukozu fault: FF, Hanaore fault: HF, Median Tectonic Line: MTL, Nojima fault: NF, and Yanagase fault: YF. Other abbreviations are Itoigawa-Shizuoka tectonic line: ISTL, Kyoto: Ky, Nagoya: Na, Osaka: O. Inset shows the plate-tectonic setting of Japanese islands. Eurasian plate: EU, Izu Peninsula: IP, North American plate: NA, Pacific plate: PA, Philippine Sea plate: PH. Thick arrows denote convergence directions between the Pacific and North 
shows a complete fault-slip datum comprising the attitude and slip direction of the fault. The direction is indicated by slickenlines on the fault plane. Figures (b) and (c) show the "sense-only" data obtained from faults on which slickenlines are not observed but whose sense of faulting is known from, for example, fault scarps and stream offsets. Either strike-slip sense or dip-slip sense of shear is known in (b), and both are known in (c). The possible slip directions of the footwalls are constrained within the range indicated by the semicircle and quadrant drawn on the fault plane. Figures (d-f) show the fault-slip data expressed in tangent-lineation diagrams [Twiss and Gefell, 1990] improved by Sato [2006]. Panels (d), (e), and (f) correspond to (a), (b), and (c), respectively. Figures (g-i) are graphs showing the fitness functions (bold lines) used in stress inversion, which can deal with all the types of the fault-slip data to determine the state of stress responsible for the

Figure 3. Tangent-lineation diagram of the complete and sense-only fault-slip data observed fault movements. Figure (g) shows a fault with the complete data and the misfit angle $d$ is between the theoretical and observed slip directions. Figures (h) and (i) show the case of a sense-only datum and $d$ is defined as the angle formed by the theoretical slip direction and the central line of the semicircle or the fan.

Figure 4. Paired stereograms showing the range of stress conditions admissible for the obtained from the active faults in the study area. See Figure 2 for the explanations fault-slip data in Figure 3. The stress ratios and principal orientations of the conditions are indicated by rainbow colors and lower-hemisphere, equal-area 
projections. Stars denote the optimal orientations. The small circles are the

$344 \quad$ solution.

345

346 Figure 5. Optimal stress axes (open stars) and calculated theoretical slip directions

347 (white arrows) plotted on a tangent-lineation diagram with a lower-hemisphere,

348 equal-area projection. The fault-slip data are the same as that in Figure 3. The

349 fault-slip data shown in red are inconsistent with the theoretical slip directions.

$350 \quad$ Note that most of the data agree with the theoretical slip directions. 


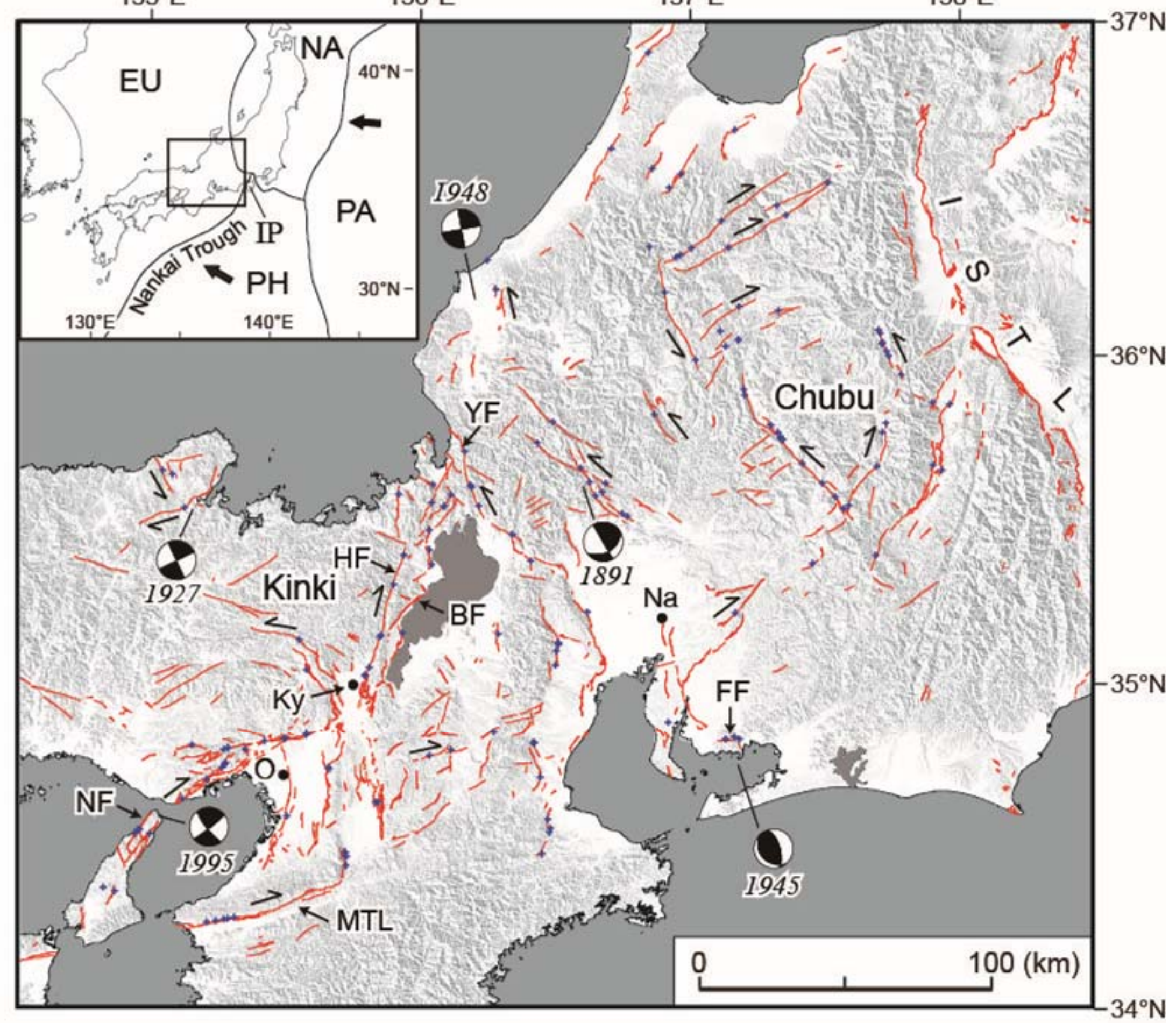

Figure 1. 
Complete datum

(a)

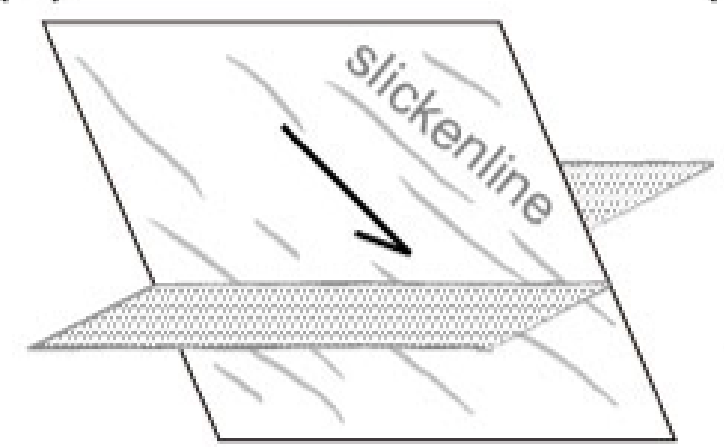

(d)

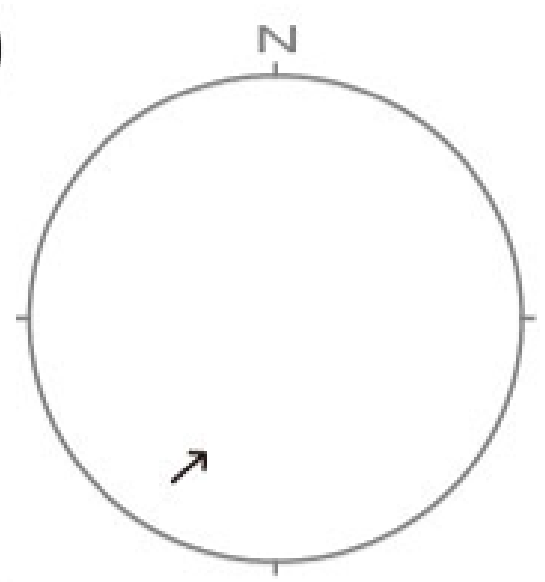

(g)

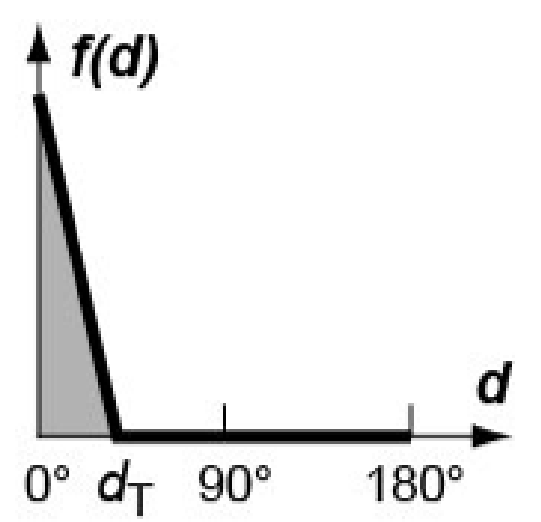

Figure 2.

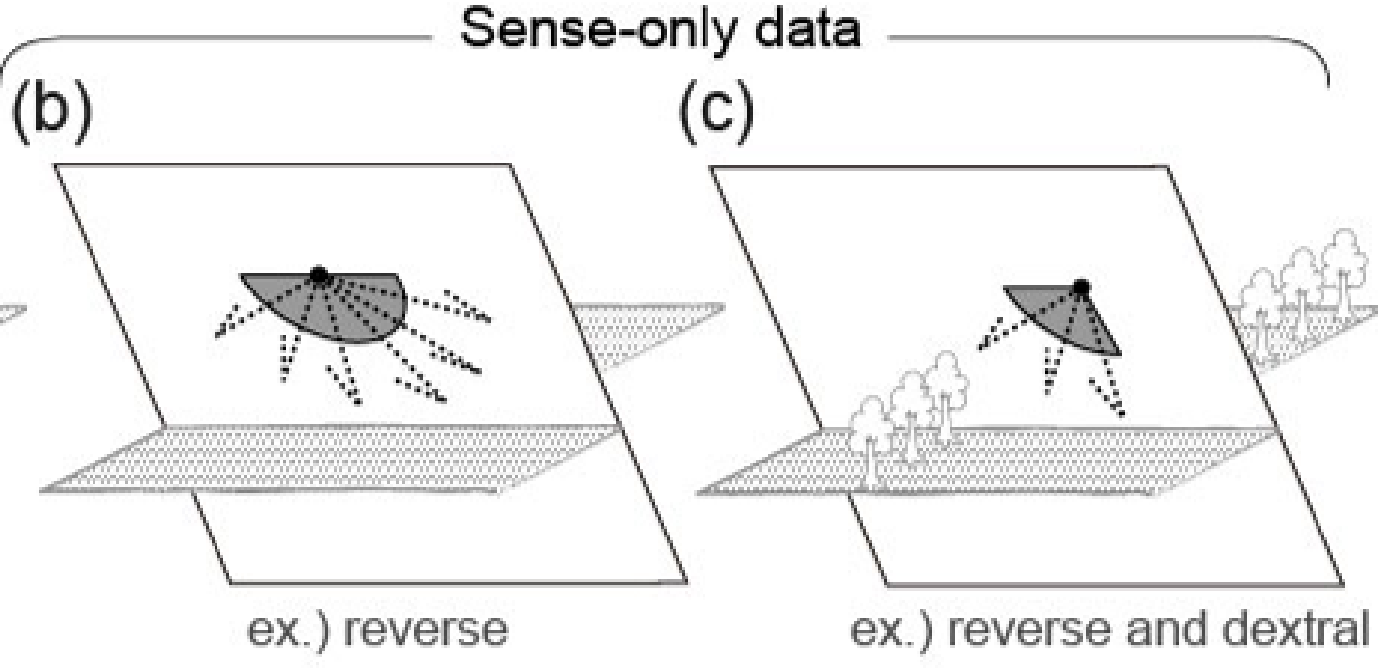

(e)

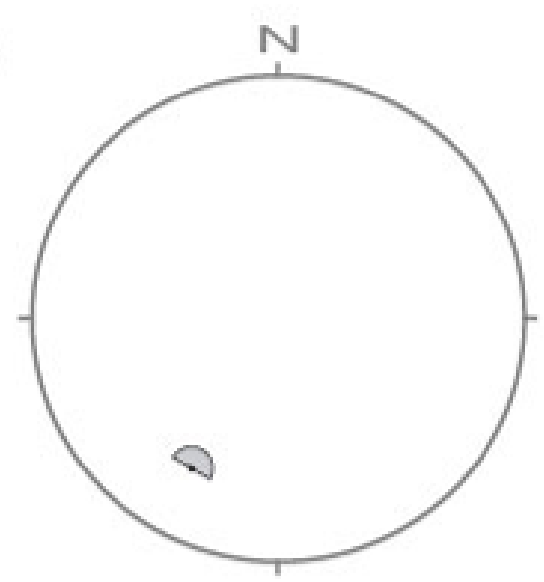

(h)

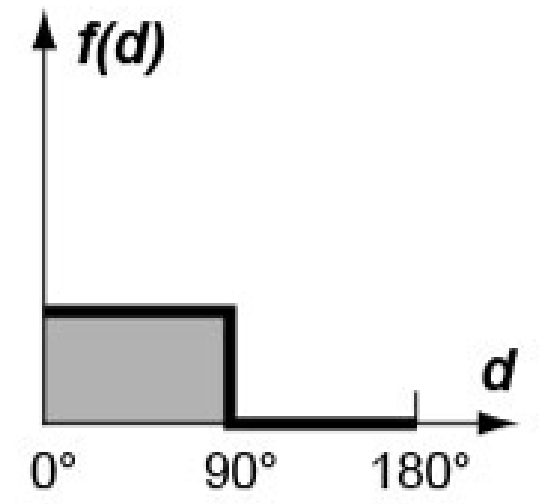

$\Phi \otimes \hookleftarrow \nearrow \uparrow$ (f)

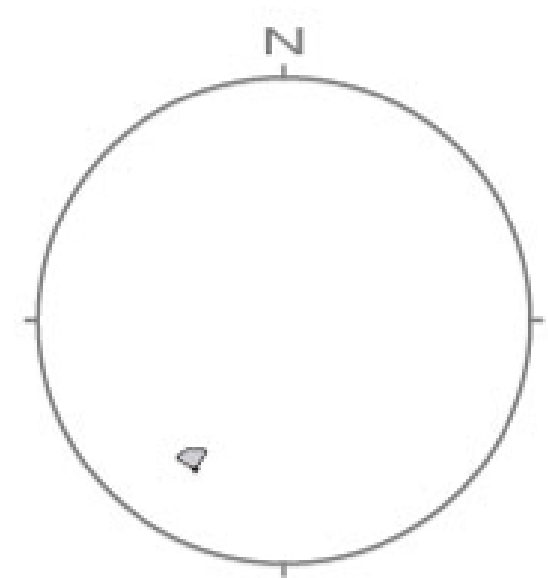

(i)

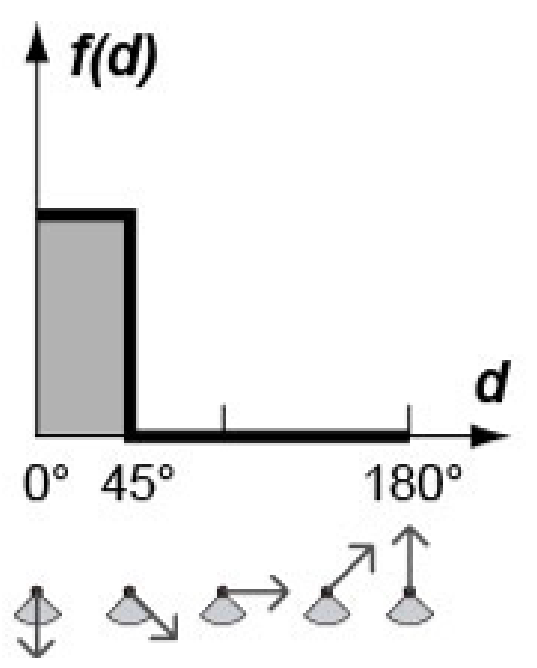




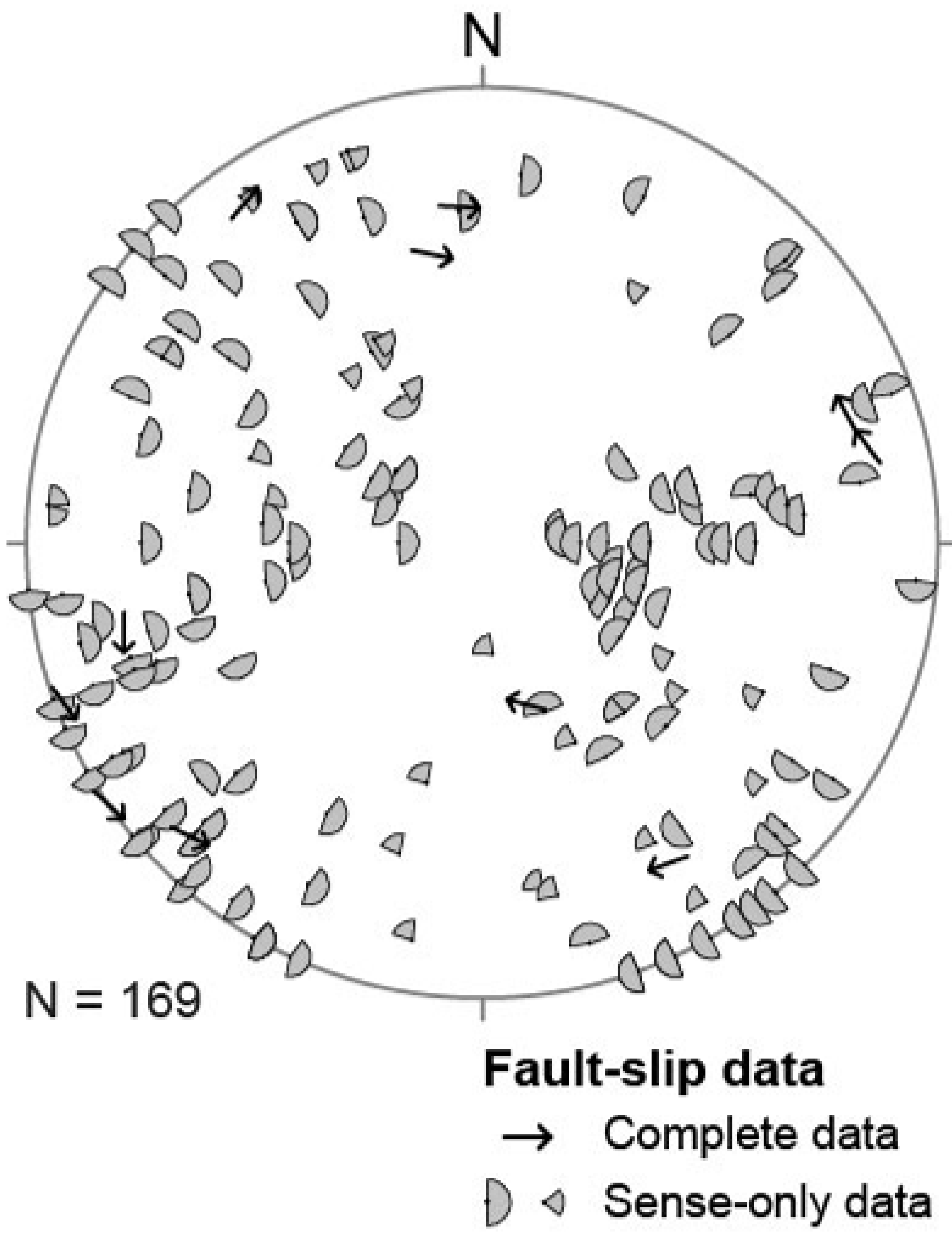

Figure 3. 


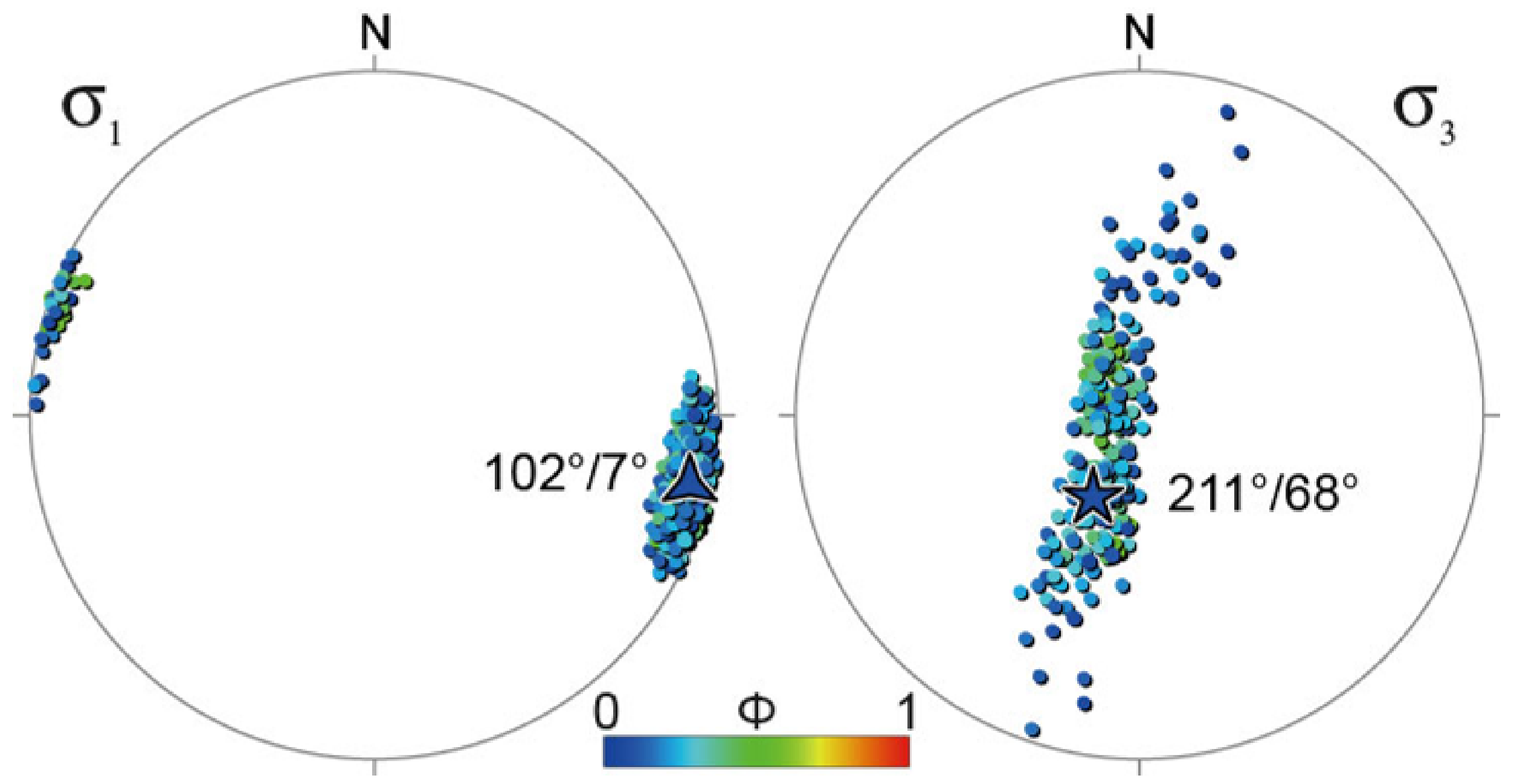

Figure 4. 


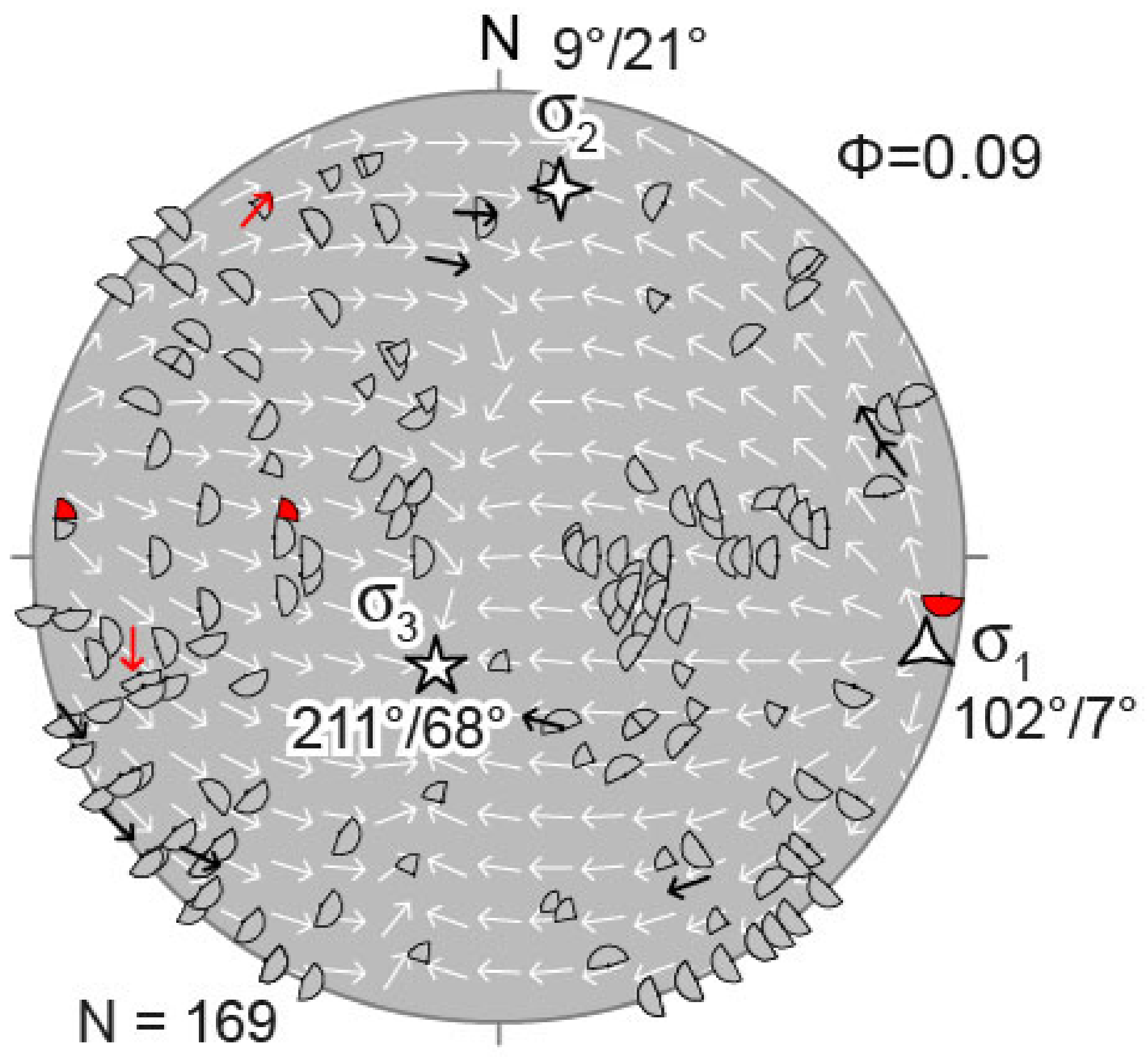

Fault-slip data with small misfit with large misfit

Complete data

Sense-only data

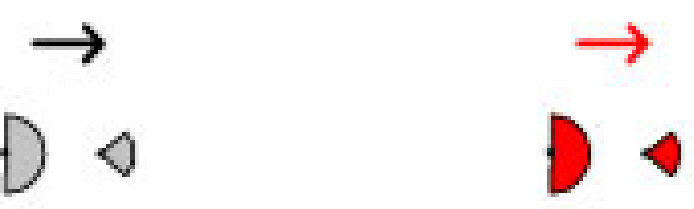

Theoretical slip direction for optimal stress condition

Figure 5. 


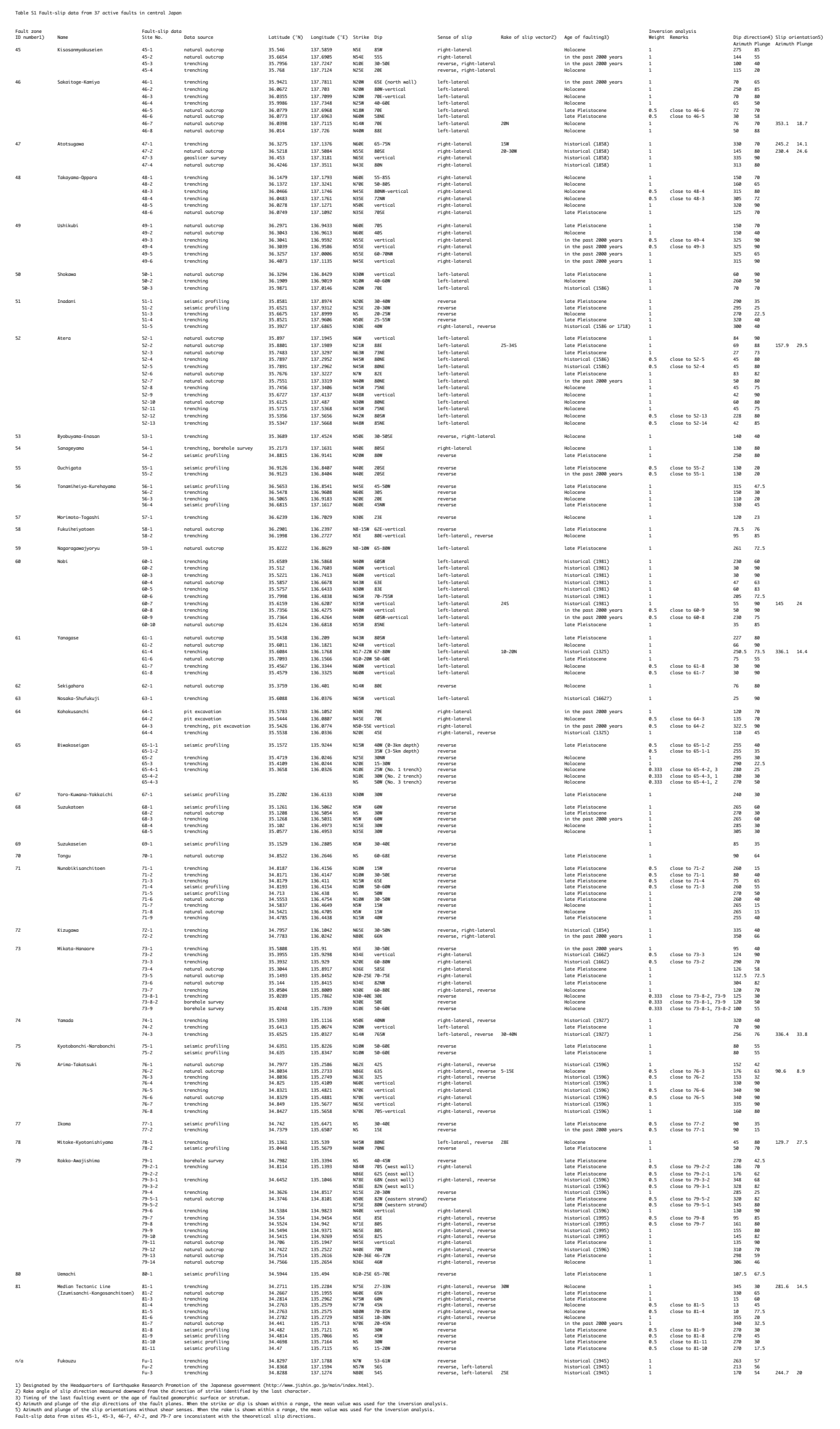

